\title{
Genetic Background-Dependent Thrombotic Microangiopathy Is Related to Vascular Endothelial Growth Factor Receptor 2 Signaling during Anti-Glomerular Basement Membrane Glomerulonephritis in Mice
}

\author{
Laurent Mesnard, ${ }^{* \dagger \dagger}$ Dominique Cathelin, ${ }^{* \dagger}$ Sophie Vandermeersch, ${ }^{* \dagger}$ Cédric Rafat, ${ }^{* \dagger}$ Yosu Luque, ${ }^{* \dagger}$ Julie Sohier, ${ }^{* \dagger}$ \\ Dominique Nochy, ${ }^{8 \top}$ Loïc Garcon, Patrice Callard, ${ }^{* *}$ Chantal Jouanneau, ${ }^{* \dagger}$ Marie-Christine Verpont, ${ }^{* \dagger}$ Pierre-Louis Tharaux, ${ }^{\boldsymbol{9} \dagger \dagger}$ \\ Alexandre Hertig, ${ }^{* \dagger \dagger}$ and Eric Rondeau* ${ }^{* \dagger}$ \\ From INSERM Unité UMR-S 1155, * Rare and Common Kidney Diseases, Matrix Remodeling and Tissue Repair, Hôpital Tenon, Paris; UMR-S 1155, ${ }^{\dagger}$ Rare \\ and Common Kidney Diseases, Matrix Remodeling and Tissue Repair, the Sorbonne Universités, UPMC University Paris, Paris; Emergency Nephrological \\ and Renal Transplantation, ${ }^{\ddagger}$ the APHP, Hôpital Tenon, Paris; the Anatomy and Pathology Service, ${ }^{\S}$ the APHP, Hôpital Européen Georges-Pompidou, and \\ Université Paris V, Paris; Université Paris Descartes, "Sorbonne Paris Cité, Paris; the Biological Immunology and Hematology Service, "the APHP, Hôpital \\ Saint-Antoine, and Sorbonne Universités, UPMC University Paris, Paris; the Anatomic Pathology Service, ${ }^{* *}$ the APHP, Hôpital Tenon, and Sorbonne \\ Universités, UPMC University Paris, Paris; and the Paris Cardiovascular Research Centre (PARCC), ${ }^{\dagger \dagger}$ INSERM, Paris, France
}

Accepted for publication

May 27, 2014.

Address correspondence to Laurent Mesnard, M.D., Ph.D., or Eric Rondeau, M.D., Ph.D., INSERM UMR 1155, Hopital Tenon, 4 rue de la Chine, 75020 Paris, France. E-mail: laurent. mesnard@tnn.aphp.fr or eric. rondeau@tnn.aphp.fr.

\begin{abstract}
Because genetic background plays a pivotal role in humans and in various experimental models, we carefully monitored its impact on glomerular pathological characteristics during experimental anti-glomerular basement membrane glomerulonephritis (anti-GBM-GN), using two leading mouse strains, 129S2/SvPas (129Sv) and C57bl/6J (B6J). These mice exhibited different severities of renal failure, hypertension, and glomerular lesions, according to their genetic background. In addition to the classic glomerular proliferative lesions, glomerular thrombotic microangiopathy (TMA) was found as a common genetic backgrounddependent histopathological hallmark of anti-GBM-GN, combined with hemolytic anemia and thrombocytopenia. Glomerular expression profiling, using microarrays and Western blot analysis in B6J TMAresistant and 129Sv TMA-prone mice, demonstrated major differences in vascular endothelial growth factor (VEGF)/VEGF receptor (VEGFR) 2 pathways, despite similar Vegfa expression levels. Further analysis revealed a lower basal glomerular endothelial Vegfr2 expression level in 129Sv TMA-prone mice compared with B6J TMA-resistant mice. This difference was even more pronounced during anti-GBM-GN, explaining why an exogenous VEGFA supply failed to rescue any 129Sv TMA lesions. Conversely, the systemic blocking of Vegfr2 amplified TMA lesions only in B6J mice. Herein, we specified the role that genetic background plays in determining, in particular, the level of Vegfr2 expression. We also demonstrated that glomerular Vegfr2dependent TMA lesions are an underevaluated common hallmark of anti-GBM-GN in mice. (Am J Pathol 2014, 184: 2438-2449; http://dx.doi.org/10.1016/j.ajpath.2014.05.020)
\end{abstract}

Genetic background is of paramount importance to the response to injury in many experimental models, as in the progression of various forms of kidney disease. ${ }^{1-4}$ The molecular basis of these genetic differences, however, is poorly understood. The passive model of anti-glomerular basement membrane glomerulonephritis (anti-GBM-GN)-also known as nephrotoxic nephritis-is useful for analyzing the cellular and molecular mechanisms of the glomerular injury. ${ }^{5-7}$ Previous studies demonstrated the role of $\mathrm{T}$ and $\mathrm{B}$ cells in this process, as well as various cytokines, such as tumor necrosis factor- $\alpha$, IL-1, IL-12, and interferon- $\gamma .^{8,9}$ In addition to these immune effectors, intrinsic glomerular cells seem to play an

Supported by INSERM, Faculté de Médecine Pierre et Marie Curie, European Renal Association-European Dialysis and Transplant Association grant ERAEDTA ALTF 74-2010 (D.C.) and Académie de Médecine grant (C.R.).

L.M. and D.C. contributed equally to this work.

Disclosures: DC101 antibody was provided by ImClone Systems (Eli Lilly and Company, New York, NY). 
active role as well. ${ }^{10}$ Indeed, they modulate inflammatory and thrombotic pathways and contribute to the severity of glomerular lesions. ${ }^{10,11}$

In the anti-GBM-GN, the genetic background of the mice has been shown to modulate the severity of the renal injuries. ${ }^{1,3}$ Indeed, among other strains, $129 \mathrm{~Sv}$ mice were demonstrated to be more prone to severe glomerular disease than B6J mice. ${ }^{1} \mathrm{In}$ these studies, however, as often in animal experiments using different genetic backgrounds, the molecular mechanisms underlying such differences were not determined. This question is important because these differences may have human counterparts. Indeed, specific signaling pathways that may modulate the severity of human renal diseases may be strongly affected by the genetic background, given the large genomic diversity observed in the human population. This diversity has been circumvented in mice by both backcrossing and inbreeding strategies, leading to actual congenic strains. ${ }^{12,13}$ For historical reasons, single mutants have been made from embryonic stem cells coming from either $129 \mathrm{~Sv}$ or, more recently, B6 strains. ${ }^{14,15}$ Despite some technological amelioration in the generation of mutant mice, a mixed genetic background still is frequently observed. ${ }^{12-15}$ This issue is exacerbated today with sophisticated multitargeted genetically engineered mice mutants (double or triple knockout, conditional, inducible, or not). These multiple-targeted mutant mice have been generated through diverse crossbreeding strategies made from diverse single mutants sometimes generated from diverse backgrounds, nurturing potentially underestimated genetic background-related experimental bias.

To better understand the glomerular lesion generation and their genetic background-related pathological features; we deliberately limit our study to the two aforementioned leading strains. As expected, we confirmed that the anti-GBM-GN was more severe in $129 \mathrm{~Sv}$ than in $\mathrm{B} 6 \mathrm{~J}$ mice. We pointed out that the major genetic background-related pathological differences are mainly related to the severity of glomerular endothelial injury. Furthermore, the severity of tubular injuries or even the importance of the renal infiltration by immune effectors ( $\mathrm{T}$ cells in particular) was actually not genetic background related as opposed to glomerular injuries. Finally, we demonstrated the existence of genetic background-related thrombotic microangiopathy (TMA) glomerular lesions. These lesions, as TMA systemic expressions (anemia and thrombocytopenia), have been underestimated during the passive anti-GBM-GN. Our results also indicate that this genetic background-dependent pathological feature of the anti-GBM-GN model could be related to a genetic background-dependent glomerular vascular endothelial growth factor receptor (Vegfr) 2 imbalance.

\section{Materials and Methods}

\section{Animals and Induction of Experimental Passive Anti-GBM-GN}

All mice (C57BL/6J and 129S2SvPAs) were provided by the Charles River Laboratories (L'Arbresle, France). Female mice (aged 10 to 12 weeks) were used in all experiments, with 10 mice per group in each experiment. Passive experimental anti-GBM was induced, as previously described, using a decomplemented sheep anti-rat GBM serum prepared as described previously. ${ }^{16,17}$ The serum meets all criteria of anti-GBM-GN/nephrotoxic nephritis (eg, fixation along the glomerular structure), principally the GBM (Supplemental Figure S1). Similar glomerular lesions were obtained with purified IgG, previously described. ${ }^{18}$ The quantity of lipopolysaccharide found in our sera was $<0.04$ endoxin units. Passive nonaccelerated anti-GBM-GN was induced by i.v. administration of a total of $1.5 \mathrm{mg}$ total protein/g body weight over 3 consecutive days (days 0,1 , and 2). This protocol was popularized by Salant and Cybulsky, ${ }^{6}$ according to the seminal work done by Morley and Wheeler ${ }^{19}$ in mice. Renal injuries were evaluated on day 4 or 10 as needed. Control mice were injected with phosphate-buffered saline (PBS) or sheep pre-immune sera.

\section{Measurement of Systolic Arterial Pressure}

Systolic arterial pressure (measured in $\mathrm{mmHg}$ ) was measured with a tail-cuff sphygmomanometer adapted for the mouse using an automated system (MC 4000 BP analysis system; Hatteras Instruments, Inc., Cary, NC). To avoid variation in blood pressure due to day cycle, all measurements were performed between 9 and 11 AM. Animals were accustomed to the system for several days before measurements were taken. Ten measurements from each mouse were taken at 2 minute intervals and then a mean value was determined.

\section{Measurement of Hemoglobin Count and Platelet Count}

Analyses were conducted from $20-\mu \mathrm{L}$ blood samples with dedicated EDTA tubes (Melet Schloesing Laboratories, Osny, France). Calibrated veterinary automated equipment (MS9 blood counting equipment; Melet Schloesing Laboratories) was used for all measurements.

\section{Measurement of Urinary Protein Excretion}

All mice were acclimated to metabolic cages with free access to food and water for 8-hour urine collection. Urinary protein concentration was normalized to urinary creatinine concentration, and values were expressed as $\mathrm{g} / \mathrm{mmol}$ creatinuria. Plasma samples were taken at the moment of sacrifice, and creatinemia or blood urea nitrogen (BUN) was determined by a KONELAB automater (Thermo Scientific, Waltham, MA).

\section{Transmission Electron Microscopy}

Animals were perfused with $2.5 \%$ glutaraldehyde in 0.1 $\mathrm{mol} / \mathrm{L}$ sodium phosphate buffer at $\mathrm{pH}$ 7.4. Kidneys were removed, cut into small pieces, and immersed in $2.5 \%$ glutaraldehyde containing $1 \%$ tannic acid in $0.1 \mathrm{~mol} / \mathrm{L} \mathrm{PBS}$ 
for 2 hours at $4^{\circ} \mathrm{C}$. Samples were post-fixed with $1 \% \mathrm{OsO}_{4}$, dehydrated, and embedded in epoxy resin. Ultrathin sections were stained with uranyl acetate and lead citrate and then examined under a Philips CM10 electron microscope (Philips Innovation Services, Eindhoven, the Netherlands).

\section{Scanning Electron Microscopy Analysis}

Mice were perfused by $2.5 \%$ glutaraldehyde in $0.1 \mathrm{~mol} / \mathrm{L}$ sodium phosphate buffer at $\mathrm{pH}$ 7.4. Kidney slices were then fixed with glutaraldehyde and cut with a razor blade. The specimens were washed in phosphate buffer and then treated with $1.0 \% \mathrm{OsO}_{4}$ for 2 hours. After being washed again in phosphate buffer, the specimens were dehydrated in a graded series of ethanol and submitted to standard scanning electronic microscopy protocols. The specimens were then examined in a scanning electron microscope (model JSM-6301F; JEOL, Tokyo, Japan) at $15 \mathrm{keV}$.

\section{Immunofluorescence Analysis of Fibrin Deposits and Immunohistological Staining of Vegfr2}

Fibrin deposition was first detected on Masson's trichrome and, therefore, confirmed by immunofluorescence on $6-\mu \mathrm{m}$ cryosections. Slides were incubated for 1 hour with fluorescein isothiocyanate-conjugated goat anti-mouse fibrin, diluted 1:50 (Nordic Immunological Laboratories, Tilburg, the Netherlands). Glomerular fibrin deposition was assessed using a semiquantitative protocol, as previously described. ${ }^{20}$ Vegfr2 was revealed using a two-layer technique on cryosections with a primary rabbit anti-mouse Vegfr2 antibody (Santa Cruz Biotechnology, Inc., Heidelberg, Germany).

\section{Isolation of Glomeruli}

Decapsulated glomeruli were isolated as previously described. $^{21,22}$ Briefly, freshly isolated renal cortex was mixed and digested by $2 \mathrm{mg} / \mathrm{mL}$ collagenase I (Gibco; Life Technologies, Saint-Aubin, France) in RPMI 1640 medium (Life Technologies) for 2 minutes at $37^{\circ} \mathrm{C}$, and then collagenase I was inactivated with RPMI 1640 medium plus $10 \%$ fetal calf serum. Tissues were then passed through a $100-\mu \mathrm{m}$ cell strainer and a 40- $\mu \mathrm{m}$ cell strainer (BD Falcon, Le Pontde-Claix, France) in PBS (Euromedex, Souffelweyersheim, France) plus $0.5 \%$ bovine serum albumin (Euromedex). Glomeruli, adherent to the $40-\mu \mathrm{m}$ cell strainer, were removed from the cell strainer with PBS plus 5\% bovine serum albumin injected under pressure, and then washed twice in PBS. Isolated glomeruli were then picked up in radioimmunoprecipitation assay buffer (Santa Cruz) supplemented with orthovanadate (Santa Cruz), phenylmethylsulfonyl fluoride (Santa Cruz), protease inhibitor cocktail (Calbiochem, Merck Chimie SAS, Fontenay sous Bois, France), and $\mathrm{NaF}$. They were then frozen at $-80^{\circ} \mathrm{C}$ for protein extraction or picked up in RNeasy Lysis Buffer (Qiagen) and frozen at $-80^{\circ} \mathrm{C}$ for total RNA extraction.
Western Blot Analysis from ex Vivo Glomerular Extracts

Glomerular lysates $(10 \mu \mathrm{g}$; radioimmunoprecipitation assay buffer and kinase inhibitor cocktail) were fractionated by SDSPAGE NuPAGE 4/12\% gels (Invitrogen, Life Technologies) under reducing conditions and blotted with rabbit anti-Vegfa antibody (Lab Vision/NeoMarkers, Fremont, CA), Vegfr2 and Vegfr2 Y1175 (Cell Signaling Technology Europe, B.V. Leiden, the Netherlands), or VEGFR1 (Santa Cruz). This process was followed by incubation with horseradish peroxidase-conjugated goat anti-rabbit IgG (Amersham, Arlington Heights, IL) for 2 hours at room temperature in 5\% PBSTween buffers. The membrane was stripped and reprobed with horseradish peroxidase-conjugated anti-mouse $\beta$-actin or hsc70 (Hspa8) to control protein loading, and antibodies were detected by enhanced chemiluminescence-plus on autoradiography films (Fuji Film, Asnières, France). Relative quantification was made using ImageJ software version 1.46r (NIH, Bethesda, MD).

\section{Gene Expression Profiling in Isolated Glomeruli}

Anti-GBM-GN disease was induced in disease-sensitive strains (129Sv) and resistant strain (B6). Glomerular RNA were next profiled using microarrays (Affymetrix GeneChip MOE 430 2.0; Affymetrix, Santa Clara, CA) on day 4 of the glomerulonephritis with standard Affymetrix protocol. RNA quality check, cDNA synthesis, labeling, and microarray analysis were performed by the Affymetrix Resource Facility core of PartnerChip (Genopole, Evry, France). The quality of total RNA was monitored by Agilent 2100 Bioanalyzer (Agilent Technologies, Palo Alto, CA) following the manufacturer's instructions. Generation of double-stranded cDNA, preparation and labeling of cDNA, hybridization to 4302.0 Mouse Genome Arrays, washing, and scanning were performed according to the standard Affymetrix protocol.

All comparisons of mRNA expression levels between groups were performed using unpaired $t$-tests with the Genespring GX software (Agilent Technologies, Palo Alto, CA). To correct for multiple testing, a false-discovery rate of 5\% was applied. Genes were identified as differentially expressed if they showed a fold change of at least 1.5 with $P$ $<0.05$. The data discussed in this publication have been deposited in the National Center for Biotechnology Information's Gene Expression Omnibus (http://www.ncbi. nlm.nih.gov/geo; accession number GSE56236).

\section{Pathway Analysis}

The Genomatix Pathways System-GePS Software (Genomatix Software GmbH, Munich, Germany) was applied to elucidate putative pathways associated with the gene expression changes in glomeruli of disease-prone mice (129S2/SvPas) versus disease-resistant mice (C57BL/6J), each time compared with their own respective non-disease control 
mice. Genomatix GePS uses information extracted from public and proprietary databases to display canonical pathways or to generate and extend networks on the basis of literature data. Pathway data were collected from the Pathway interaction database. This includes several pathways imported from BioCarta (http://cgap.nci.nih.gov/ Pathways/BioCarta_Pathways). These data and their generation are described in detail by Schaefer et al. ${ }^{23}$

\section{qPCR on Glomerular mRNA}

To validate the expression differences observed using microarrays, we quantified glomerular mRNA expression of Vegfr2, Vegfr1, neuropilin 1 (Nrp1), and Vegfa at day 4 using quantitative PCR (qPCR). Podocin from the entire renal cortex was analyzed on day 10 . Glomeruli were extracted using different sieving procedures, as previously described. ${ }^{20,22}$ Contamination with tubular fragments was $<10 \%$, as assessed by phase-contrast microscopy. RNA was extracted from the glomerular extract using a Qiagen micro kit (Qiagen S.A., Courtaboeuf, France). Reverse transcription with Superscript II (Gibco) was used to convert RNA into cDNA, which was then amplified by PCR with a LightCycler 480 (Roche Diagnostics, Meylan, France); SYBR Green (Fast Start DNA Master SYBR Green I; Roche Diagnostics), and specific primers for target mRNA designed by Roche (Universal Probe Library). Results are expressed as $2^{-\delta \mathrm{Cp}}$.

\section{Injection of VEGFA (VEGFA165) Recombinant Protein}

Human VEGFA 165-sf9 (1 $\mu \mathrm{g}$; Biovendor, Brno, Czech Republic) was s.c. injected (half-life of 6.2 hours, as previously described $^{24}$ ) four times on days $0,1,2$, and 3 after nephrotoxic sera injection. Mice were sacrificed on day 4 .

\section{Mouse Vegfr2 Blocking and Injection of the Rat Anti- Mouse Vegfr2 Antibody}

We used an antibody made in rat supplied by ImClone Systems (a wholly owned subsidiary of Eli Lilly and Company, New York, NY). ${ }^{25,26}$ This antibody is specific of mouse Vegfr2, without cross-reactivity, and was injected i.p. (500 $\mu \mathrm{g}$ every 48 hours) during 9 days in total. Proteinuria and histological parameters were all evaluated at days 4 and 9 , respectively.

\section{Statistical Analysis}

Quantitative analyses of histological features were performed using blinded coded slides. A total of 10 mice per experiment were analyzed in two or three separate experiments, and the results are expressed as means \pm SEMs. Differences were compared using an unpaired $t$-test with Welch correction. When variance differed significantly, a Mann-Whitney test was performed. All statistical analyses were performed using
GraphPad Prism version 5.0 (GraphPad Software, San Diego, CA). Fibrin score deposition was compared using a two-sided Fisher's exact test. Differences were considered to be significant when $P<0.05$.

\section{Results}

The Severity of Anti-GBM-GN Is Dependent on Genetic Background

We challenged $129 \mathrm{~Sv}$ mice using a decomplemented nephrotoxic serum from the same batch. After anti-GBM serum injection, we were able to demonstrate the characteristic deposits of anti-GBM sheep antibody along the GBM membrane in particular. Similarly, mice developed anti-sheep $\mathrm{IgG}$, colocalized to GBM membrane (Supplemental Figure S1). Mortality at day 20 was $100 \%$ in $129 \mathrm{~Sv}$ compared with $40 \%$ in B6J mice $(P<0.005)$ (Figure $1 \mathrm{~A})$, showing that genetic background is an important factor in anti-GBM-GN. Similarly, proteinuria and acute renal failure at day 10 were more pronounced in $129 \mathrm{~Sv}$ than in B6J mice (Figure 1, B and C). Renal inflammatory cell infiltration, a common hallmark of anti-GBM-GN severity, was quantified at a similar time point (day 10). Concerning the renal recruitment of macrophages (Figure 1F) and T cells (Figure 1, G and $\mathrm{H}$ ), we failed to find any significant difference in cellular infiltration between strains; only the recruitment of polymorphonuclear cells (Figure 1I) appeared different, specifically elevated, in the more resistant B6J strain.

\section{Crescentic and Endothelial Lesions, But Not Tubular Injuries, Are GB Dependent}

Histological lesions, in particular crescentic lesions (Supplemental Figure S2, A-C), were quantified at day 10 of the disease (Figure 1, D-F). B6J mice developed fewer glomerular lesions than 129Sv mice (Figure 1D). Podocytic necrosis or ballooning, with or without cystic lesions (Supplemental Figure S2H), were frequently observed and occasionally led to the disruption of the glomerular architecture, forming pseudocrescents or crescents, a classic feature of this model (Supplemental Figure S2, A and B). Tubular lesions were obviously not different between strains. The pseudocrescentic lesions were also assessed by electron microscopy, and the down-regulation of podocyte mRNA markers was also quantified (Supplemental Figure S2, E-G). At an early time point of the glomerulonephritis (day 4), all podocyte mRNA markers (podocin, nephrin, and Wt1), measured from ex vivo isolated glomeruli, were found more elevated in $\mathrm{B} 6 \mathrm{~J}$ mice than in 129Sv mice. Podocin mRNA level was also different at the basal stage, lower in 129Sv mice than B6J mice. Genetic background-dependent podocytic lesions were visible by scanning electron microscopy (Supplemental Figure S2, $\mathrm{H}-\mathrm{M})$. We discovered that dedifferentiation of podocytes occurred earlier in $129 \mathrm{~Sv}$ compared with B6J mice 

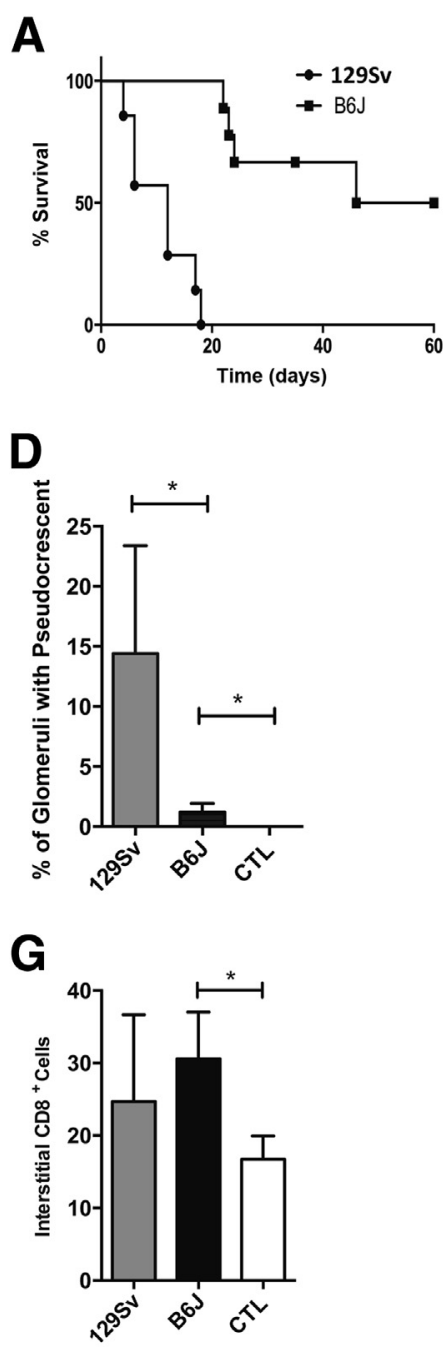

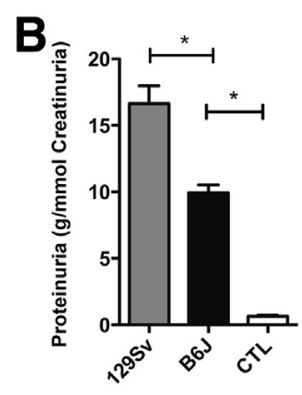

E

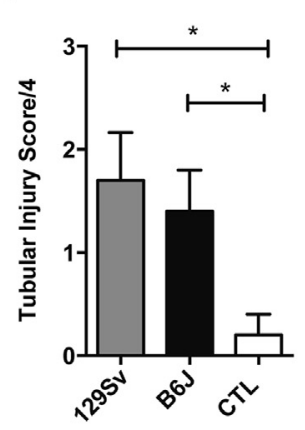

H

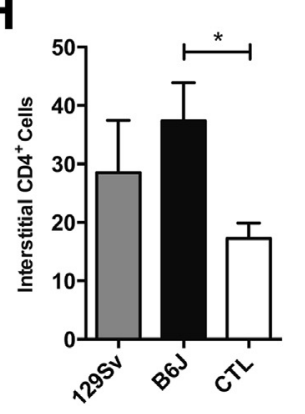

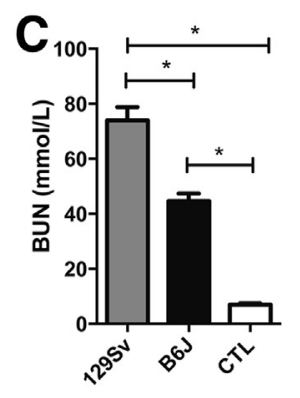

$\mathbf{F}$

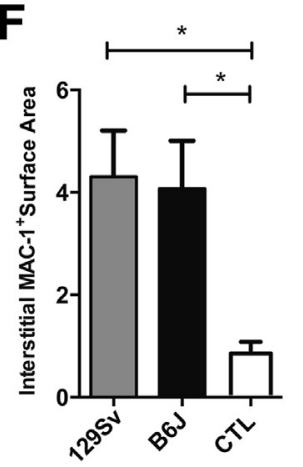

I

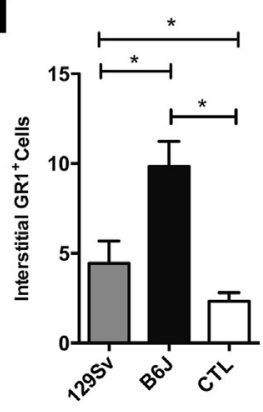

Figure 1 Genetic background and glomerular lesions are associated with anti-GBM-GN severity. A: After anti-GBM serum injection, mortality is largely dependent on mouse strain $(P<0.005$, Kaplan-Meier for B6J versus $129 \mathrm{~Sv}$ ); B6J mice were largely protected. $0 \mathrm{n}$ day 10 of the experimental model, proteinuria (B) and BUN (C) were lower in B6J mice and maximal in $129 \mathrm{~Sv}$ mice. D: Glomerular lesions, represented herein by the percentage of glomeruli with crescents or pseudocrescents at day 10 , were higher in $129 \mathrm{~Sv}$ mice than in B6J mice. $\mathrm{E}$ : Tubulo-interstitial lesions were not different between strains. Renal inflammatory cell infiltration, a hallmark of the anti-GBM-GN model, was also quantified by detection of Mac-1, reflecting macrophages $(\mathbf{F}), \mathrm{CD}^{+}$and $\mathrm{CD}_{4}^{+}$reflecting T cells ( $G$ and $\mathbf{H}$, respectively), and $\mathrm{Gr}^{+}$-highlighting polymorphonuclear cells (I). I: Despite an important infiltration of these cells into the kidney, no differences could be related to the genetic background of the mice, except for $\mathrm{Gr}^{+}$staining, which was inversely correlated to disease severity. Results are expressed as means \pm SEM $(n=10)$. Data are representative of four isolated experiments, each with 5 to 10 animals per group. ${ }^{*} P<0.05$ (Student's $t$-test with Welsh correction or MannWhitney test). CTL, control.
(Supplemental Figure S2L compared with Supplemental Figure S2I); we noted the regression of major foot processes. Podocytes appeared vacuolated, with evident cytoplasmic protrusions (blebs) explaining some aforementioned pathological aspects at a later time point. For B6J mice, glomerular lesions at day 4 were limited by light microscopy (Supplemental Figure 2C). At day 10, lesions were scarce and consisted of double contours visible at high magnification, and by electron microscopy, an effacement of the foot processes, which appeared flattened (Supplemental Figure S2, D, I, and J).

\section{TMA Lesions Are Associated with Classic Hematological Features of Human TMA}

The glomerular endothelium is also a potential target of injury in the anti-GBM-GN model, and local activation of the coagulation system is common. ${ }^{27}$ Thus, endothelial lesions were assessed and quantified by light and electronic microscopy. Fibrin deposits were numerous in 129Sv mice (Figure 2C) and visible by transmission electron microscopy (Figure 2N). In B6J mice, tiny dots of fibrin deposits were visible, but glomerular thrombosis was virtually never seen (Figure 2B). In contrast, 129Sv mice often had massive coagulation of the glomerular capillary (Figure 2A). In both strains, but especially in 129Sv mice, we observed endothelial lesions that were highly reminiscent of TMA, such as double contours, subendothelial spaces, and fibrin deposits, but to a different extent according to their genetic background. Double contours were mainly observed in B6J mice, and fibrin deposits were mostly seen in 129Sv mice (Figure 2, D and E). TMA was further confirmed by transmission electron microscopy analysis. Similar to TMA lesions described in humans, we found large loss of endothelium (Figure 2M), platelet accumulation, and existence of subendothelial spaces (Figure 2, $\mathrm{N}$ and $\mathrm{O}$, respectively).

As in human, we looked for systemic evidence of TMA. At day 10, profound anemia was observed, along with reticulocytosis (Figure 2, H and I), scarce circulating helmet cells (schistocytes) (Figure 2J), and thrombocytopenia (Figure 2G). Here again, anemia and thrombocytopenia 
were more severe in 129Sv mice than in B6J mice (Figure 2, $\mathrm{F}$ and $\mathrm{G})$. Finally, blood pressure also increased, and hypertension was more pronounced as the renal disease became more severe (ie, in 129Sv mice) (Figure 2K). All
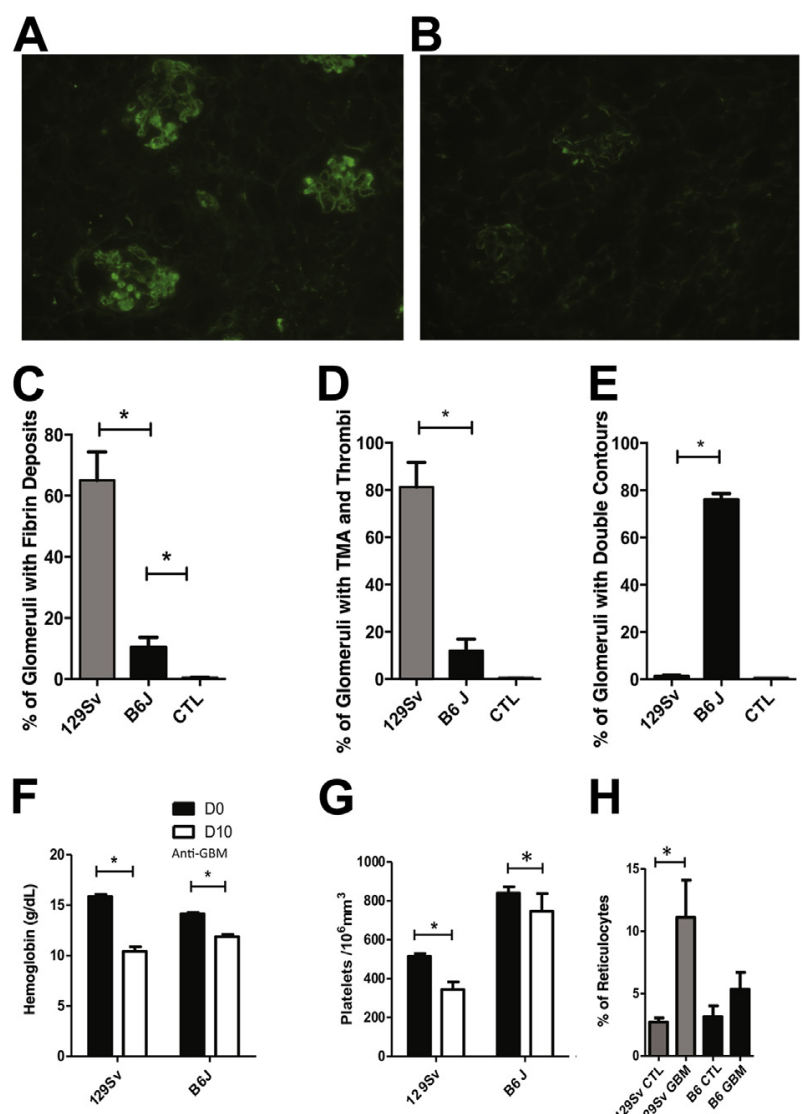

\section{G}

$\mathrm{H}$
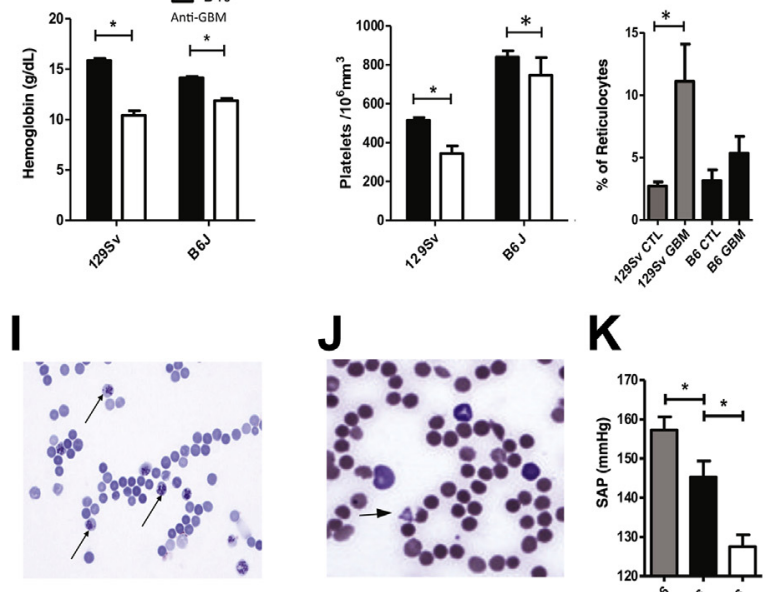

$\mathbf{K}$

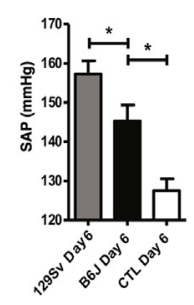

$\mathbf{L}$

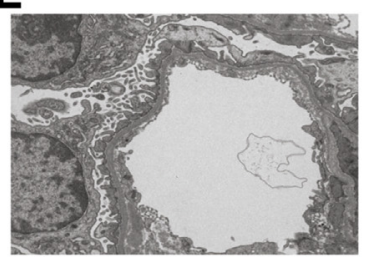

M

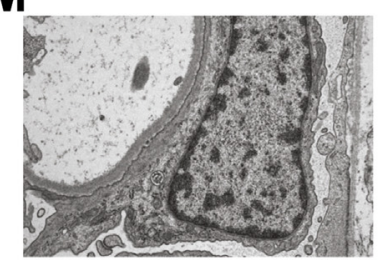

$\mathbf{N}$

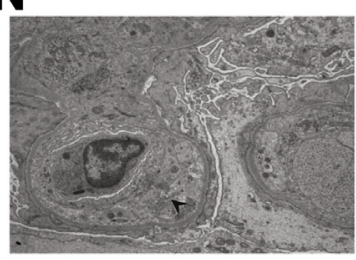

these parameters have been used to characterize human TMA.

VEGF/VEGFR2 and Hypoxia Pathways Are the Main Pathways Involved in Genetic Background-TMA Severity

To further understand the mechanism of the GB-dependent TMA, we performed microarray expression profiling of mRNA isolated from glomeruli in disease-prone mice $(129 \mathrm{~Sv})$ and disease-resistant mice (B6J) at an early time point (day 4) ( $n=3$ per group, 12 mice in total). Interestingly, the VEGFR and hypoxia-inducible pathways were implicated in TMA-prone mice (Figure $3 \mathrm{~A}$ and Table 1). $\mathrm{Kdr}$ (Vegfr2) appears as one of the most differentially expressed genes between non-nephritic B6J and 129Sv mice (basal level). Top differentially expressed genes involved in both the hypoxia and VEGFR pathways are depicted in the heatmap (Figure 3B). A common pathway (shared by both B6J and $129 \mathrm{~Sv}$ mice) showed that differentially expressed genes were enriched in the NF- $\kappa \mathrm{B}$ and matrix metalloprotease pathways (Figure 3B and Table 1). Furthermore, cell cycle pathways seemed more specifically involved in B6J-resistant mice (Table 1).

\section{Endothelial Glomerular VEGFR2 Expression Is Lower in TMA-129Sv-Prone Mice in Comparison to B6-TMA- Resistant Mice}

To confirm these differences and to determine whether an insufficient signaling of the VEGFR1/2 pathways caused the severity of the glomerular TMA, levels of Vegfr2 and Vegfr1 and one of their coreceptor Nrp1 were also determined from ex vivo-isolated glomeruli. We found similar expression of Nrp1 and Vegfr1 in both strains at the basal

\footnotetext{
Figure 2 TMA is a yet unrecognized hallmark of anti-GBM-GN, which is maximal in $129 \mathrm{~Sv}$ mice and less severe in B6J mice. The most striking difference between strains was glomerular fibrin deposits (129Sv mice in $\mathbf{A}$ and B6J mice in B). C: We quantified fibrin deposits at day 10 of anti-GBMGN. Fibrin deposits with double contour were maximal in 129Sv mice (D), and the percentage of double contour pattern alone was maximal in B6J mice (E). Quantification of hemoglobin showing anemia (F); platelet count showing thrombocytopenia (G). H and I: The intensity of associated reticulocytosis (indicated by arrows in I) was also analyzed in the two strains (blood stained with brilliant cresyl blue). J: Scarce schistocytosis was also observed (arrows). Note the virtual absence of thrombocytes on May-Grünwald-Giemsa staining, confirming thrombocytopenia. K: AntiGBM-GN also induces hypertension in both strains measured at day 6 , again maximal in the 129Sv strain. Early TEM examination of the glomerular endothelium at day 4 (representative normal aspect in $\mathbf{L}$ ) shows its virtual absence in $129 \mathrm{~Sv}$ mice (M), and the existence in 129Sv of subendothelial space (arrowhead in $\mathbf{N}$ ) with deposited platelets in $\mathbf{0}$ (arrow indicates platelets and an asterisk marks the existence of a subendothelial space). The same type of lesion is also visible to a lesser degree in B6J mice. All results are expressed as means $\pm \operatorname{SEMS}(n=10)$. Data are representative of three isolated experiments, each with 5 to 10 animals per group. ${ }^{*} P<0.05$ (Mann-Whitney test). Original magnification, $\times 10,000$. CTL, control.
} 
A

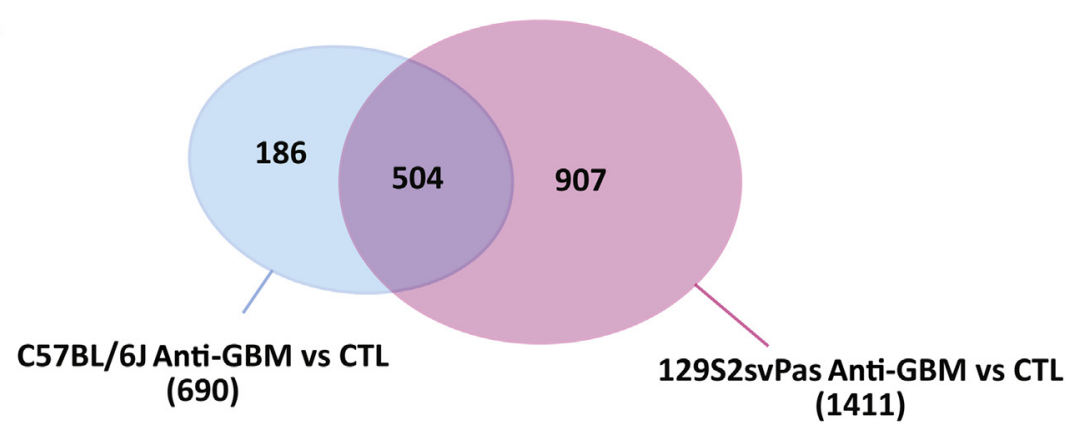

B

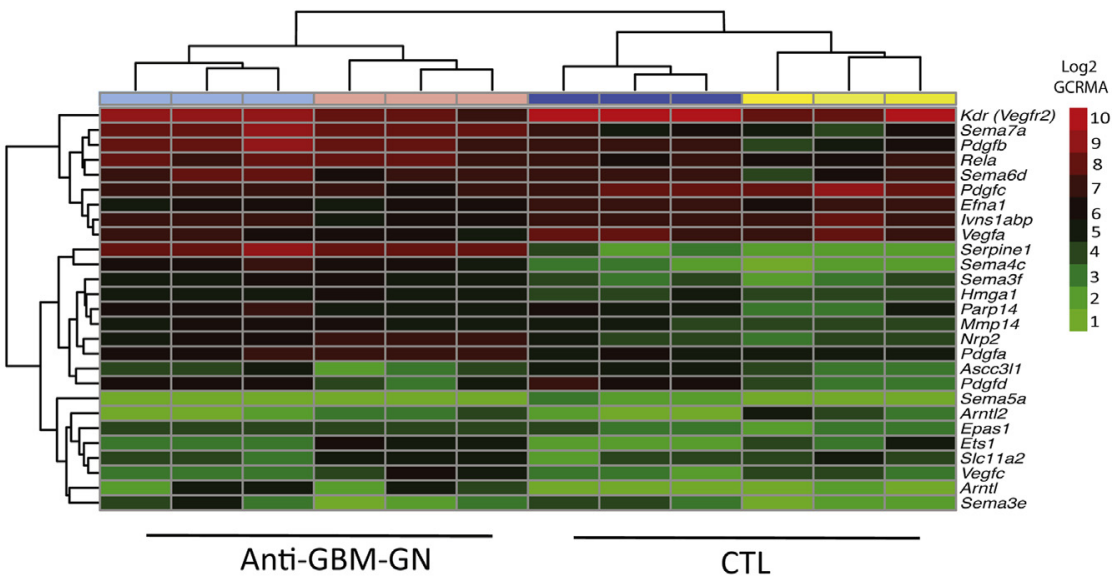

Figure 3 Venn diagram and representation of glomerular DNA microarray showing the importance of VEGFR pathway during antiGBM-GN, according to mice genetic backgrounds. Anti-GBM-GN was induced in disease-sensitive (129Sv) and resistant (B6J) strains, then glomerular RNA was analyzed using DNA microarrays on day 4 of the glomerulonephritis. A total of 690 transcripts $(186+504)$ were modulated in B6J strain compared with its own control (CTL; $n=3)$; conversely, 1411 transcripts $(504+907)$ were modulated in 129Sv compared again with its own control $(n=3)$. A: Venn diagram representing the repartition of transcripts. B: Heatmap representations focusing on VEGFR and hypoxia-related genes; major differences are found according to the genetic background, either at the basal level or after glomerulonephritis. Note the striking difference between $\mathrm{Kdr}$ (Vegfr2) expressions at the basal level. Three biological replicates were included for each strain. Gene chip robust multiarray averaging (GCRMA) intensity values have been plotted and clustered in the heatmap.

level either at the mRNA (Figure 4, A and B) or protein (Figure 4, C-E) level. At day 4, the level of Vegfr1 was slightly decreased in B6J mice, but finally not found to differ between strains. Contrary to Vegfr1 and confirming our microarray data, Vegfr2 (Kdr) was significantly lower in $129 \mathrm{~Sv}$ mice at the basal level compared with B6J mice, suggesting that a genetic background-determined process may especially tune vegfr2 level. Similarly, following the course of the nephritis, both Vegfr2 mRNA and total Vegfr2 protein were found to be lower in TMA-prone mice either at day 4 (Figure 4, F-I and K) or even at day 10 by immunohistochemistry (Figure 4, G and $\mathrm{H}$ ).

For technical reasons, we failed to evaluate vegfr 1 phosphorylation, but were able to quantify the glomerular Vegfr2-Y1175 phosphorylation, reflecting Vegfr2 functionality. Consistently, the level of Vegfr2-Y1175 appeared higher in B6J mice compared with 129Sv mice (Figure 4, J and $\mathrm{K}$ ). In addition, using confocal microscopy, we pointed out that glomerular VEGFR-2 expression was mainly limited to glomerular endothelial cells (Supplemental Figure S3). Again, its expression appeared higher in B6J than in 129Sv strain, at day 4 of the anti-GBM-GN (Supplemental Figure S3, C versus D). Taken together, these data suggest that the Vegfr2 expression and its Y1175 phosphorylation by glomerular endothelial cells may be on a genetic background dependency.
Systemic VEGFA Supply Fails to Rescue Genetic Background-TMA Lesions and, Conversely, Specific Vegfr2 Blocking Aggravates B6 Mice Only

By using ex vivo-isolated glomeruli, we failed to find any defect in glomerular levels of VegfA by Western blot analysis, despite a difference in its associated mRNA (Figure 5, A and B). In vivo, early VEGFA supplementation in nephritic animals (every day for 4 days in total, beginning day 0) exerted no benefit regarding BUN level (Figure 5D) in any strain. We even found an increase in proteinuria in the VEGFA B6-treated mice (Figure 5C). Conversely, to confirm the genetic background-Vegfr2 dependency during anti-GBM-GN, we specifically blocked Vegfr2 using a rat anti-mouse Vegfr2 antibody (DC101). In such conditions, after the Vegfr2-blocking antibody injection, B6J mice were strikingly aggravated, contrary to $129 \mathrm{~Sv}$ mice (Figure 5, E-H). Glomerular fibrin deposits and glomerular thrombosis were higher, especially in B6J mice (Figure 5H). The surrogate systemic TMA parameters (anemia and thrombocytopenia) were found to be especially aggravated in B6J anti-vegfr2treated mice versus B6J non-treated mice (Figure 4, I and $\mathrm{J}$ ). Thus, the systemic Vegfr2 blocking aggravated the TMA-resistant B6J mice but failed to aggravate significantly the $129 \mathrm{~Sv}$ TMA-prone mice. 
Table 1 Strain-Dependent Gene Expression Pathways during Anti-GBM-GN

\begin{tabular}{|c|c|c|c|}
\hline Variable & Canonical pathway & Pathway ID & $P$ value \\
\hline \multirow{6}{*}{$\begin{array}{l}186 \text { Transcripts found } \\
\text { only in } \text { C57BL/6J }\end{array}$} & Polo-like kinase 1 & PW_PLKI1_MUS_MUSCULUS & $1.18 \times 10^{-4}$ \\
\hline & Polo-like kinase 3 & PW_PLKI3_MUS_MUSCULUS & $1.39 \times 10^{-4}$ \\
\hline & Aurora kinase & PW-AURORA_MUS_MUSCULUS & $1.56 \times 10^{-4}$ \\
\hline & Cell division cycle 2 & PW-CDC2_MUS_MUSCULUS & $1.71 \times 10^{-4}$ \\
\hline & Signal transducer and activator of transcription & PW-STAT_MUS_MUSCULUS & $3.84 \times 10^{-3}$ \\
\hline & Granzyme B & PW-GZMB_MUS_MUSCULUS & $9.75 \times 10^{-3}$ \\
\hline & $N F-\kappa B$ & PW_NFKB_MUS_MUSCULUS & $5.21 \times 10^{-9}$ \\
\hline & Mitogen-activated protein kinase & PW_MAPK_MUS_MUSCULUS & $2.12 \times 10^{-8}$ \\
\hline & Focal adhesion kinase & PW_FAK_MUS_MUSCULUS & $3.71 \times 10^{-8}$ \\
\hline & Tissue inhibitor of metalloproteinase & PW_TIMP_MUS_MUSCULUS & $4.75 \times 10^{-8}$ \\
\hline & Rho Ras homologue & PW_RHOA_MUS_MUSCULUS & $9.37 \times 10^{-8}$ \\
\hline & Caveolin 1 & PW_CAVEOLIN_MUS_MUSCULUS & $5.64 \times 10^{-7}$ \\
\hline only in $129 S 2 S v P a s$ & $\begin{array}{l}\text { Hypoxia-inducible factor, } \alpha \text { subunit } \\
\text { (basic helix loop helix transcription factor) }\end{array}$ & PW_HIF1A_MUS_MUSCULUS & $2.74 \times 10^{-6}$ \\
\hline & Integrin & PW_INTEGRIN_MUS_MUSCULUS & $2.75 \times 10^{-5}$ \\
\hline & Matrix metalloproteinase & PW_MMP_MUS_MUSCULUS & $3.02 \times 10^{-5}$ \\
\hline & Peroxisome proliferator-activated receptor $\gamma$ & PW_PPARG_MUS_MUSCULUS & $8.73 \times 10^{-4}$ \\
\hline & Integrin-linked kinase & PW_ILK_MUSS_MUSCULUS & $1.25 \times 10^{-4}$ \\
\hline & Nitric oxide synthase & PW_NOS_MUS_MUSCULUS & $1.26 \times 10^{-4}$ \\
\hline & Cyclin D1 & PW_CCND1_MUS_MUSCULUS & $1.62 \times 10^{-4}$ \\
\hline & Protein kinase $\mathrm{C}$ & PW_PKC_MUS_MUSCULUS & $1.84 \times 10^{-4}$ \\
\hline & $\begin{array}{l}\text { FK506 binding protein } 12 \text { and rapamycin-associated } \\
\text { protein, mTor }\end{array}$ & PW_MTOR_MUS_MUSCULUS & $2.96 \times 10^{-4}$ \\
\hline
\end{tabular}

\begin{abstract}
Major strain-dependent gene expression pathway differences in isolated glomeruli at day 4 of the anti-GBM-GN (more than twofold up or down, $P<0.05$ ), corresponding to Venn diagram in Figure 3. Analysis of the common gene set represented in Figure 3 (504 transcripts) found VEGFR and matrix metalloproteinase pathways as top-ranking pathways involved in the pathogenesis of glomerular injury. Analysis of transcripts implicated only in $129 \mathrm{SV}$ found VEGFR and hypoxia-inducible factor pathways strikingly modulated. Angiogenesis pathways seem largely implicated in 129Sv mice compared with B6J mice. Conversely, in this last strain, cell cycle pathways represented by polo-like kinase/aurora kinase are largely implicated. Pathways were built using GePS software (http://www.genomatix.de).
\end{abstract}

\section{Discussion}

Our study shows that, in the anti-GBM-GN model, TMA lesions are associated with classical glomerular epithelial proliferative lesions. Endothelial lesions explain fibrin deposition and microthrombosis. These features are largely genetic background related, mimicking human TMA lesions. Anti-GBM-GN-associated TMA lesions have been largely underrecognized in previous studies. In addition, we demonstrated that the glomerular VEGFR2 pathway activation is genetically determined. Given the current pathophysiological features of TMA, genetic background-related VEGFR2 peculiarities may explain the difference observed in disease severity between the two strains of mice.

The anti-GBM-GN model is a widely used experimental model mainly adapted to decipher crescentic glomerulonephritis (CG) and its associated pathophysiological characteristics. ${ }^{6,9,28}$ Using different strains, Xie et al ${ }^{1,3}$ were able to demonstrate the large genetic background dependency of the anti-GBM-GN model. The scarcity of the lesions in B6J mice could explain why TMA lesions were, until now, poorly described. The severity of TMA lesions could be even more unpredictable in ultramixed genetic backgrounds, a situation inherent to modern multitargeted mouse models, in which 129Sv embryonic stem cells are widely used. ${ }^{12,13,29,30}$ Our observation may also explain the large phenotypic variations related to VEGFR2 pathways, in particular in the developmental study. ${ }^{18,29,31-33}$ In addition, we assigned anti-GBM$\mathrm{GN}$ as a potential, yet poorly recognized, experimental renal TMA model, especially in $129 \mathrm{~Sv}$-prone mice strains. Indeed, we demonstrate the presence of hemolytic anemia featured by red blood cell abnormalities, thrombocytopenia, and acute renal failure with nephrotic range proteinuria and hypertension. All these abnormalities have been found in humans with hemolytic uremic syndrome. ${ }^{34}$ Finally, the major molecular pathways involved in glomeruli during anti-GBM-GN were related to VEGFR pathways.

Our Vegfr2-blocking strategy confirmed not only the dependency of the anti-GBM-GN model to this receptor, but also pointed out its association with genetic background. 

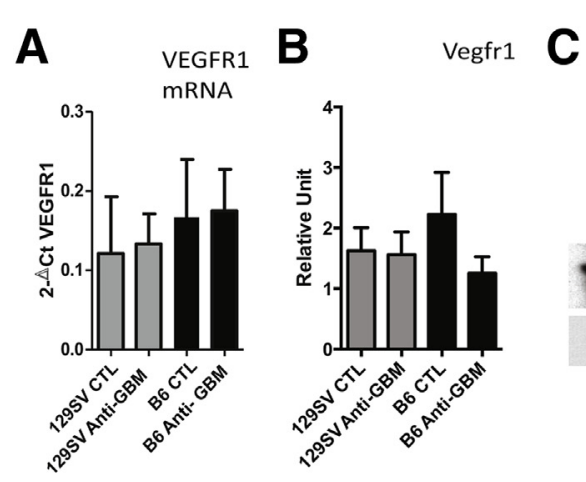

D

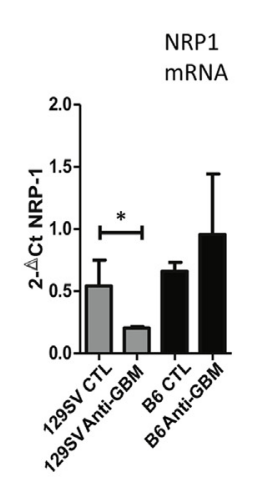

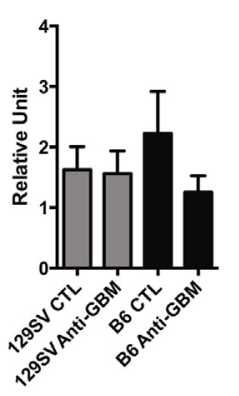

E

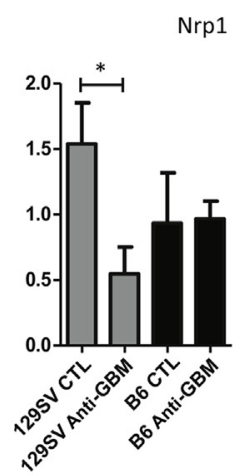

F

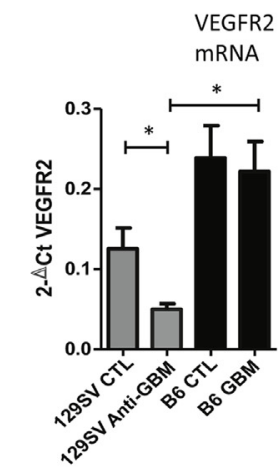

G

B6

Day 10

H

129SV

Day 10

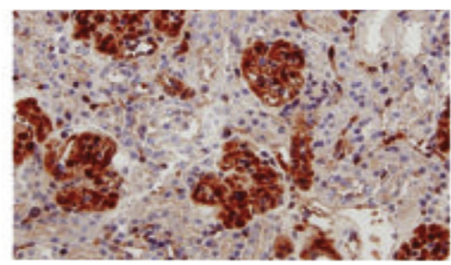

Vegfr2

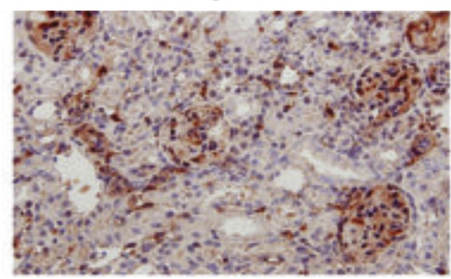

I

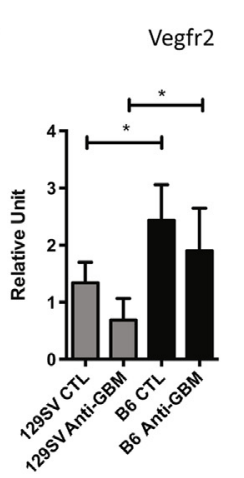

$J$

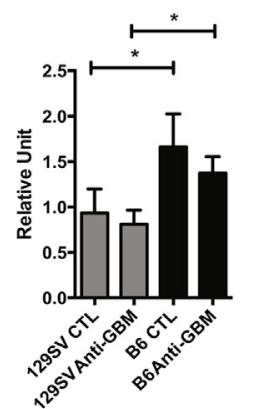

K

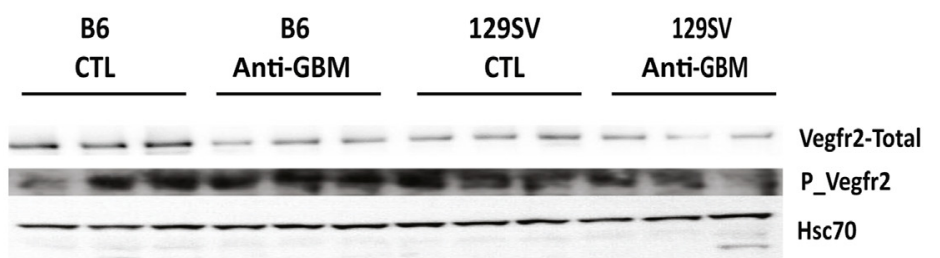

Figure 4 Podocytic fate and glomerular VEGF pathway analyses during early stages of anti-GBM-GN. Vegfr1 or Nrp1 expression were found to be similar in glomerular extracts, as quantified by $\mathrm{PPCR}$ (A and $\mathbf{D}$, respectively) and Western blot analysis (B and $\mathbf{E}$, respectively); a representative Vegfr1 Western blot analysis (C). $\mathbf{F}-\mathbf{K}$ : Only the glomerular Vegfr2 level and its associated phosphorylation is different during the early phase of anti-GBM-GN. Intense staining is found at day 10 in B6J mice (G) compared with 129Sv mice (H). K: Western blot analysis of the representative Vegfr2 and its phosphorylated form. All results are expressed as means \pm SEMs $(n=8)$. Data are representative of four pooled isolated experiments, each time with at least three to five animals per group ( $n=9$ to 12 per group). ${ }^{*} P<0.05$ (Mann-Whitney test). Original magnification, $\times 400$. CTL, control.

The involvement of Vegfr2 was also largely suggested by the adverse effects of drugs associated with anti-VEGF therapies in humans. ${ }^{35-37}$ Masuda et $\mathrm{al}^{38}$ were able to demonstrate that a VEGFA supply may limit crescentic lesions during rat anti-GBM-GN model at a later time point (in the Wistar Kyoto rat strain, which is extremely sensitive to the anti-GBM-GN model). Hohenstein et al ${ }^{39}$ recently described the glomerular expression of VEGFR2 during human CG. In this work, TMA lesions were not analyzed and VEGFR2 expression was not quantified in a pure TMA context as a positive control. ${ }^{39}$ However, one study at least was able to pinpoint the existence of TMA lesions during anti-GBM-GN in 6 of 12 patients. The authors state that histological evidence of TMA may be seen in $75 \%$ of patients with anti-GBM-GN. More recently, a report discussed the relationship between TMA lesions and CG. In these two studies, TMA lesions are well described, but no pathophysiological mechanism was suggested. ${ }^{40}$ In addition, the importance of genetic background in the genesis of these lesions is not discussed. ${ }^{41}$

Interestingly, published studies have shown that murine podocytes are one of the key elements of crescentic lesion 
A
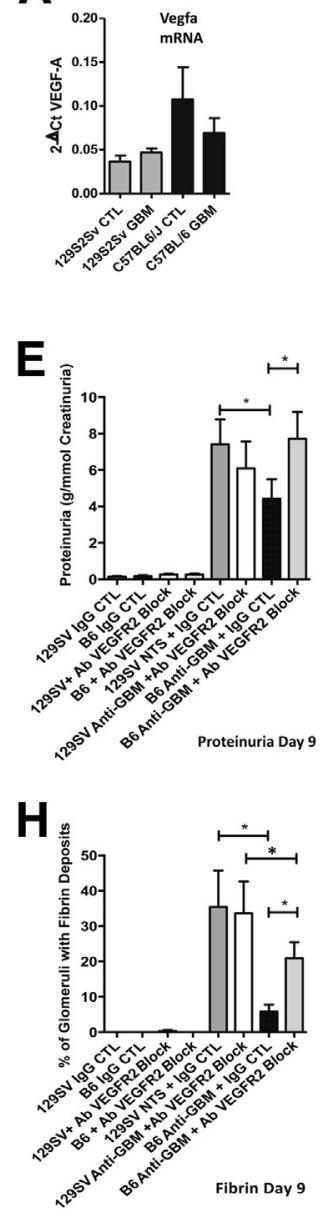

B

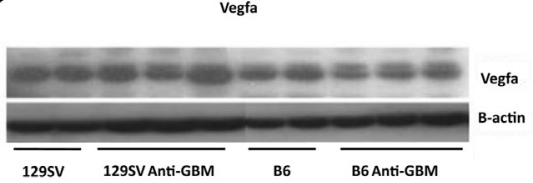

$\mathbf{F}$

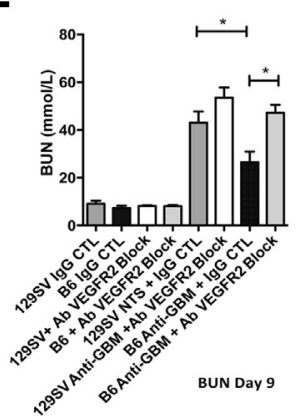

I

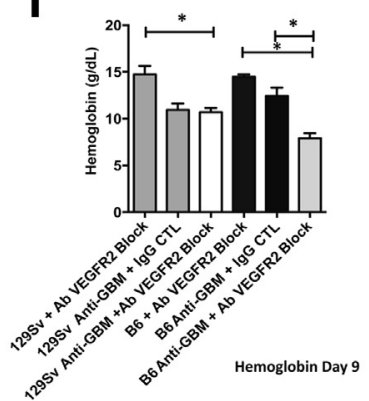

C
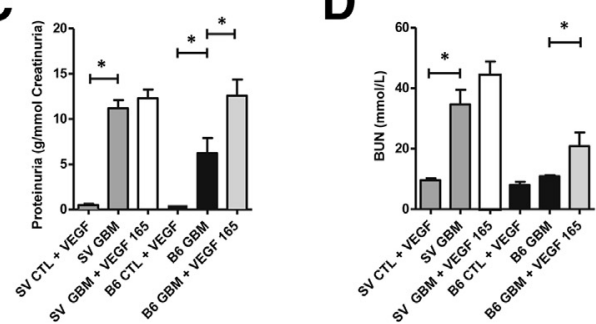

G
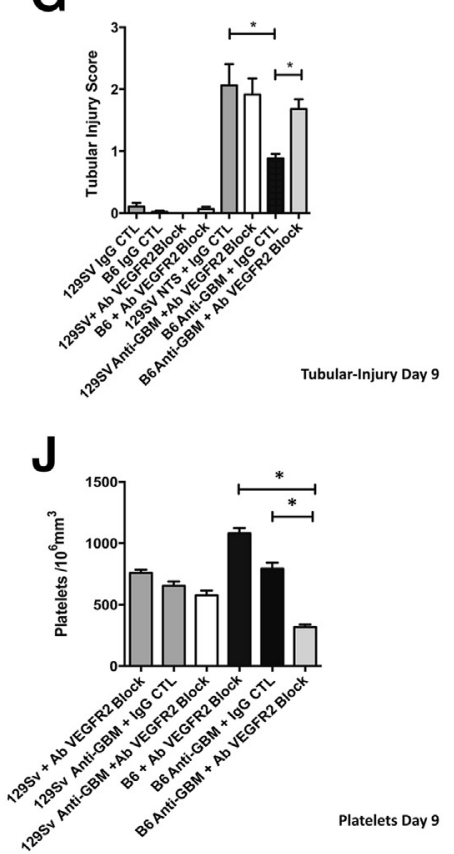

Figure 5 Systemic VEGF165A administration failed to prevent TMA lesions, but specific VEGFR2 inhibition aggravated B6J mice only. Analysis of Vegfa mRNA (B) and its associated protein (A) from glomerular lysates from both strains (B6J and 129Sv). No difference is observed in the Vegfa level between strains. C: Slight aggravation of proteinuria in B6-VEGFA-treated mice is observed. D: Conversely, the daily injection of recombinant human VEGF165A has no benefit regarding BUN level in any strain. Systemic Vegfr2 (Kdr) blocking using a rat anti-mouse Vegfr2 antibody leads to the aggravation of the anti-GBM-GN, especially proteinuria and BUN at day 9 (E and $\mathbf{F}$, respectively). G: Tubulo-interstitial lesions and score are especially aggravated after VEGFR2 blocking only in B6 mice. H: Glomerular fibrin deposits are more numerous after vegfr2 blocking in the B6J strain. At day 10 of the anti-GBM-GN, systemic TMA parameters (anemia in I and thrombocytopenia in $\mathbf{J}$ ) are clearly seen in the B6J strain after anti-vegfr2 injection. There was no glomerular toxicity in control (CTL) mice. All results are expressed as means \pm SEMs $(n=8)$. Data are representative of four isolated experiments, each time with at least five animals per group. ${ }^{*} P<0.05$ (Mann-Whitney test).

ignition, particularly in the anti-GBM-GN model. ${ }^{22,42-44}$ Herein, we demonstrated and confirmed the existence of podocytic lesions in both strains. In particular, pseudocrescent formation was evident in 129Sv. At first, we expected a lower VEGFA output from diseased podocytes, leading to glomerular endothelial dysfunction and, thus, TMA lesions. Our data cannot support this hypothesis, given that glomerular Vegfa production was finally not altered and a VEGFA supply could not reverse the disease, as previously shown in other studies. ${ }^{45,46}$ Even more, our data suggest that an exogenous supply of VEGFA could be harmful in the B6J strain, as measured by the proteinuria. This observation reinforces the fact that Vegfa responses are largely dependent on the genetic background. Furthermore, specific lesions of podocytes facilitated by inducible disruption of podocin did not lead to glomerular endothelium dysregulation or TMA in different genetic backgrounds. ${ }^{47,48}$ Thus, TMA lesions observed in the anti-GBM-GN model did not seem to be related to the Vegfa supply from podocytes, but rather to Vegfr2 signaling in endothelial cells. This hypothesis is largely sustained by our data and the findings reported in inducible $K d r / V e g f r 2$ knockout mice by Sison et al. ${ }^{49}$ The authors observed that the specific inducible Vegfr2 deletion in endothelial cells led to glomerular TMA.

The systemic blocking of Vegfr2 in both strains of mice confirmed not only the genetic background-Vegfr2 dependency of the model, but also explains why VEGFA supply was not able to rescue $129 \mathrm{~Sv}$ mice in particular. Indeed, the defect was more on the receptor than the ligand. Remarkably, comparing glomerular Vegfr2 expression, we observed an imbalance of this receptor at the basal state, 
with lower expression in 129Sv mice and higher expression in B6J mice. A higher Vegfr2 level could confer a survival effect on B6J glomerular endothelial expression or even a proliferation advantage and repairs. How to explain genetic background-Vegfr2 differential expression remains unknown at present, and further studies are needed to answer this question. Whether a similar genetic background role is involved in human glomerulonephritis is likely and will need large genetic screening with modern genomic tools to be analyzed.

In conclusion, our work refined the role played by the genetic background during the anti-GBM-GN model and demonstrated that the genetic background determined, in particular, the level of glomerular Vegfr2 expression. The blocking of Vegfr2 worsens the disease severity and TMA lesions in anti-GBM-GN-prone, but not in anti-GBMGN-resistant, mice. We also demonstrated that glomerular Vegfr2-dependent TMA lesions are an underevaluated severity hallmark of anti-GBM-GN.

\section{Acknowledgments}

We thank Chantal Millot, Carole Martori, Corinne Da Rold, and Ismaël Drouet de la Thibauderie (Service des Explorations Fonctionnelles Rénales, Hopital Tenon, Pr Baud) for their technical assistance; Caroline Martin and Claude Kitou for providing animal housing; Isabel le Disquet [Institut de biologie intégrative (IFR-BI - IFR 83, Paris, France)] for help with scanning electron microscopy analysis; and Fanny Menard for hematological analysis. ImClone Systems (a wholly owned subsidiary of Eli Lilly and Company, NYC) provided the DC101 antibody.

\section{Supplemental Data}

Supplemental material for this article can be found at http://dx.doi.org/10.1016/j.ajpath.2014.05.020.

\section{References}

1. Xie C, Sharma R, Wang H, Zhou XJ, Mohan C: Strain distribution pattern of susceptibility to immune-mediated nephritis. J Immunol 2004, 172:5047-5055

2. Xie C, Qin X, Jonnala G, Gong Y, Yan M, Zong P, Zhou XJ, Mohan C: Enhanced susceptibility to immune nephritis in DBA/1 mice is contingent upon IL-1 expression. Clin Immunol 2007, 124:49-56

3. Xie C, Rahman ZS, Xie S, Zhu J, Du Y, Qin X, Zhou H, Zhou XJ, Mohan C: Strain distribution pattern of immune nephritis: a follow-up study. Int Immunol 2008, 20:719-728

4. Montagutelli X: Effect of the genetic background on the phenotype of mouse mutations. J Am Soc Nephrol 2000, 11(Suppl 16):S101-S105

5. Masugi M: Uber die spezifischen zytotoxischen Veranderungen der Niere und der Leber durch das spezifische Antiserum (Nephrotoxin and Hepatotoxin): Zugleich ein Beitrag zur Pathogenese der Glomerulonephritis. (Specific cytotoxic alterations of kidney and liver induced by specific anti-serum (nephrotoxin and hepatotoxin): a report about the pathogenesis of glomerulonephritis.) German. Jap Path Soc 1932, 21:329-341
6. Salant DJ, Cybulsky AV: Experimental glomerulonephritis. Methods Enzymol 1988, 162:421-461

7. El Nahas AM: Masugi nephritis: a model for all seasons. Edited by Gretz N. Experimental and Genetic Rat Models of Chronic Renal Failure. Basel, Karger, 1993, pp 49-67

8. Tipping PG, Holdsworth SR: Cytokines in glomerulonephritis. Semin Nephrol 2007, 27:275-285

9. Tipping PG, Holdsworth SR: T cells in crescentic glomerulonephritis. J Am Soc Nephrol 2006, 17:1253-1263

10. Timoshanko JR, Tipping PG: Resident kidney cells and their involvement in glomerulonephritis. Curr Drug Targets Inflamm Allergy 2005, 4:353-362

11. Tipping PG, Timoshanko J: Contributions of intrinsic renal cells to crescentic glomerulonephritis. Nephron Exp Nephrol 2005, 101: e173-e178

12. Linder CC: Genetic variables that influence phenotype. ILAR J 2006, 47:132-140

13. Simpson EM, Linder CC, Sargent EE, Davisson MT, Mobraaten LE, Sharp JJ: Genetic variation among 129 substrains and its importance for targeted mutagenesis in mice. Nat Genet 1997, 16:19-27

14. Taft RA, Davisson M, Wiles MV: Know thy mouse. Trends Genet 2006, 22:649-653

15. Linder CC: The influence of genetic background on spontaneous and genetically engineered mouse models of complex diseases. Lab Anim (NY) 2001, 30:34-39

16. Mesnard L, Keller AC, Michel ML, Vandermeersch S, Rafat C, Letavernier E, Tillet Y, Rondeau E, Leite-de-Moraes MC: Invariant natural killer T cells and TGF-beta attenuate anti-GBM glomerulonephritis. J Am Soc Nephrol 2009, 20:1282-1292

17. Hertig A, Berrou J, Allory Y, Breton L, Commo F, Costa De Beauregard MA, Carmeliet P, Rondeau E: Type 1 plasminogen activator inhibitor deficiency aggravates the course of experimental glomerulonephritis through overactivation of transforming growth factor beta. FASEB J 2003, 17:1904-1906

18. Zhu WH, Iurlaro M, MacIntyre A, Fogel E, Nicosia RF: The mouse aorta model: influence of genetic background and aging on bFGF- and VEGF-induced angiogenic sprouting. Angiogenesis 2003, 6:193-199

19. Morley AR, Wheeler J: Cell proliferation within Bowman's capsule in mice. J Pathol 1985, 145:315-327

20. Mesnard L, Rafat C, Vandermeersch S, Hertig A, Cathelin D, XuDubois YC, Jouanneau C, Keller AC, Ribeil JA, Leite-de-Moraes MC, Rondeau E: Vitronectin dictates intraglomerular fibrinolysis in immune-mediated glomerulonephritis. FASEB J 2011, 25:3543-3553

21. Schiwek D, Endlich N, Holzman L, Holthöfer H, Kriz W, Endlich K: Stable expression of nephrin and localization to cell-cell contacts in novel murine podocyte cell lines. Kidney Int 2004, 66:91-101

22. Bollee G, Flamant M, Schordan S, Fligny C, Rumpel E, Milon M, Schordan E, Sabaa N, Vandermeersch S, Galaup A, Rodenas A, Casal I, Sunnarborg SW, Salant DJ, Kopp JB, Threadgill DW, Quaggin SE, Dussaule JC, Germain S, Mesnard L, Endlich K, Boucheix C, Belenfant X, Callard P, Endlich N, Tharaux PL: Epidermal growth factor receptor promotes glomerular injury and renal failure in rapidly progressive crescentic glomerulonephritis. Nat Med 2011, 17:1521

23. Schaefer CF, Anthony K, Krupa S, Buchoff J, Day M, Hannay T, Buetow KH: PID: the Pathway Interaction Database. Nucleic Acids Res 2009, 37:D674-D679

24. Rennel ES, Hamdollah-Zadeh MA, Wheatley ER, Magnussen A, Schuler Y, Kelly SP, Finucane C, Ellison D, Cebe-Suarez S, BallmerHofer K, Mather S, Stewart L, Bates DO, Harper SJ: Recombinant human VEGF165b protein is an effective anti-cancer agent in mice. Eur J Cancer 2008, 44:1883-1894

25. Ran S, Huang X, Downes A, Thorpe PE: Evaluation of novel antimouse VEGFR2 antibodies as potential antiangiogenic or vascular targeting agents for tumor therapy. Neoplasia 2003, 5:297-307

26. Yuen D, Pytowski B, Chen L: Combined blockade of VEGFR-2 and VEGFR-3 inhibits inflammatory lymphangiogenesis in early and middle stages. Invest Ophthalmol Vis Sci 2011, 52:2593-2597 
27. Hertig A, Rondeau E: Role of the coagulation/fibrinolysis system in fibrin-associated glomerular injury. J Am Soc Nephrol 2004, 15: 844-853

28. Couser WG: Basic and translational concepts of immune-mediated glomerular diseases. J Am Soc Nephrol 2012, 23:381-399

29. Ward NL, Moore E, Noon K, Spassil N, Keenan E, Ivanco TL, LaManna JC: Cerebral angiogenic factors, angiogenesis, and physiological response to chronic hypoxia differ among four commonly used mouse strains. J Appl Physiol 2007, 102:1927-1935

30. Downing GJ, Battey JF Jr: Technical assessment of the first 20 years of research using mouse embryonic stem cell lines. Stem Cells 2004, 22: $1168-1180$

31. Rogers MS, Rohan RM, Birsner AE, D'Amato RJ: Genetic loci that control vascular endothelial growth factor-induced angiogenesis. FASEB J 2003, 17:2112-2114

32. Marques SM, Campos PP, Castro PR, Cardoso CC, Ferreira MA, Andrade SP: Genetic background determines mouse strain differences in inflammatory angiogenesis. Microvasc Res 2011, 82:246-252

33. Chan CK, Pham LN, Chinn C, Spee C, Ryan SJ, Akhurst RJ, Hinton DR: Mouse strain-dependent heterogeneity of resting limbal vasculature. Invest Ophthalmol Vis Sci 2004, 45:441-447

34. Laszik ZG, Silva FG: Hemolytic uremic syndrome, thrombotic thrombocytopenic purpura, and other thrombotic microangiopathies. Edited by Jennette JC, Olson JL, Schwartz MM, Silva FG. Heptinstall's Pathology of the Kidney. ed 6. Philadelphia, Lippincott Williams \& Wilkins, 2007, pp 676-684

35. Bollee G, Patey N, Cazajous G, Robert C, Goujon JM, Fakhouri F, Bruneval P, Noel LH, Knebelmann B: Thrombotic microangiopathy secondary to VEGF pathway inhibition by sunitinib. Nephrol Dial Transplant 2009, 24:682-685

36. Nochy D, Lefaucheur C, Hill G: VEGF inhibition and renal thrombotic microangiopathy. N Engl J Med 2008, 359:206; author reply -7

37. Frangie C, Lefaucheur C, Medioni J, Jacquot C, Hill GS, Nochy D: Renal thrombotic microangiopathy caused by anti-VEGF-antibody treatment for metastatic renal-cell carcinoma. Lancet Oncol 2007, 8: $177-178$

38. Masuda Y, Shimizu A, Mori T, Ishiwata T, Kitamura H, Ohashi R, Ishizaki M, Asano G, Sugisaki Y, Yamanaka N: Vascular endothelial growth factor enhances glomerular capillary repair and accelerates resolution of experimentally induced glomerulonephritis. Am J Pathol 2001, 159:599-608
39. Hohenstein B, Colin M, Foellmer C, Amann KU, Brekken RA, Daniel C, Hugo CP: Autocrine VEGF-VEGF-R loop on podocytes during glomerulonephritis in humans. Nephrol Dial Transplant 2010, 25:3170-3180

40. Stave GM, Croker BP: Thrombotic microangiopathy in anti-glomerular basement membrane glomerulonephritis. Arch Pathol Lab Med 1984, 108:747-751

41. Bazari H, Guimaraes AR, Kushner YB: Case records of the Massachusetts General Hospital: case 20-2012: a 77-year-old man with leg edema, hematuria, and acute renal failure. N Engl J Med 2012, 366: $2503-2515$

42. Bariety J, Mandet C, Hill GS, Bruneval P: Parietal podocytes in normal human glomeruli. J Am Soc Nephrol 2006, 17:2770-2780

43. Thorner PS, Ho M, Eremina V, Sado Y, Quaggin S: Podocytes contribute to the formation of glomerular crescents. J Am Soc Nephrol 2008, 19:495-502

44. Moeller MJ, Soofi A, Hartmann I, Le Hir M, Wiggins R, Kriz W, Holzman LB: Podocytes populate cellular crescents in a murine model of inflammatory glomerulonephritis. J Am Soc Nephrol 2004, 15:61-67

45. Eremina V, Jefferson JA, Kowalewska J, Hochster H, Haas M, Weisstuch J, Richardson C, Kopp JB, Kabir MG, Backx PH, Gerber HP, Ferrara N, Barisoni L, Alpers CE, Quaggin SE: VEGF inhibition and renal thrombotic microangiopathy. N Engl J Med 2008, 358:1129-1136

46. Eremina V, Baelde HJ, Quaggin SE: Role of the VEGF-a signaling pathway in the glomerulus: evidence for crosstalk between components of the glomerular filtration barrier. Nephron Physiol 2007, 106: p32-p37

47. Ratelade J, Lavin TA, Muda AO, Morisset L, Mollet G, Boyer O, Chen DS, Henger A, Kretzler M, Hubner N, Thery C, Gubler MC, Montagutelli X, Antignac C, Esquivel EL: Maternal environment interacts with modifier genes to influence progression of nephrotic syndrome. J Am Soc Nephrol 2008, 19:1491-1499

48. Mollet G, Ratelade J, Boyer O, Muda AO, Morisset L, Lavin TA, Kitzis D, Dallman MJ, Bugeon L, Hubner N, Gubler MC, Antignac C, Esquivel EL: Podocin inactivation in mature kidneys causes focal segmental glomerulosclerosis and nephrotic syndrome. J Am Soc Nephrol 2009, 20:2181-2189

49. Sison K, Eremina V, Baelde H, Min W, Hirashima M, Fantus IG, Quaggin SE: Glomerular structure and function require paracrine, not autocrine, VEGF-VEGFR-2 signaling. J Am Soc Nephrol 2010, 21: $1691-1701$ 